\title{
ASSESSMENT OF JOB STRESS;
}

Demographic factors in doctors working at the Tertiary Care Hospitals of Karachi.

\author{
Dr. Farhat Khan, Mr. Muhammad Bilal Azmi, Miss Mehwish Hussain, Miss Sarah Shamim Azmi
}

ABSTRACT... Background: Today medical profession is fully equipped with highly competitive roles and responsibilities which serve as high source of stress in one's daily life. Stress has it negative effects on person's life like unbearable health outcomes are among one of the prominent cause of stress linked occupational diseases. Objective: The objective of this study was to determine the job stress among different doctors working in tertiary care hospitals of Karachi and to compare it with different demographical factors. Subjects and methods: Non- experimental, cross-sectional survey was conducted at different tertiary care hospitals of Karachi. Total one hundred and thirty five doctors filled the standardized job stress questionnaire through convenient sampling method from December 2011 to April 2012. Results: Overall job stress score was $52.56 \pm 16.35$. The value of Cronbach's Alpha was $79.65 \%$. Unmarried professionals were significantly more stressed than married professionals $(p<0.0001)$. Similarly, participants with only graduate degree with less year of experience were found to have higher stress than postgraduate medical doctors. The change in the marital status, depicted by Gamma coefficient, explained the decrement of job stress observed from single to married. Conclusions: It was concluded from this study that in medical profession stress is never underestimated. Demographic factors like marital status, experience and professional qualification serve as the stress reducing factors among professional.

Key words: Cross-sectional, demographic factors, doctors, job, Stress

\section{Article Citation}

$\checkmark \quad$ Khan F, Azmi MB, Hussain M, Azmi SS. Assessment of job stress with demographic factors in doctors working at the Tertiary Care Hospitals of Karachi. Professional Med J Feb 2013;20(1):156-163.

\section{INTRODUCTION}

Today stress remains a favorite subject for research in different professions as high competitive working environment, global recessions, changes in the technological practices etc are the major contributors of stress in daily life. Much has been written on job stress as it is the incompatibility between an individual's ability and demand at work result in the inefficiency to manage the pressure associated with job ${ }^{1}$. Over the last few decades job stress especially in the field of occupational health has received great importance ${ }^{2}$. Job stress usually affects the healthcare providers more than the organizations as they may experience physiological or psychological suffering or both $^{3}$. Things like individual's competency, selfconfidence, professional or social conflicts and demands are the vital influencing parameters and their divergence mostly equate with the concept of job related stress ${ }^{4}$.

Scientific data from past researches supports the existence of more job stress in white- collar workers because often they work to meet the difficult deadlines or the heavy burden of work does not give them time to relive the pressure ${ }^{5}$. Organizational dependent factors like workloads pressure, low salary structure, role ambiguity, performance pressure, long working hours etc are the prominent source for inducing stress in $\mathrm{job}^{6}$. Medical profession experiences numerous types of professional stressors. For example most of the doctors employed in healthcare sectors are often observed to be working beyond their contracted working timings to fulfill the demand of their profession $^{7}$. Interestingly the impact of heavy workload and dissatisfaction is strongly associated with the occurrence of stress ${ }^{8}$.

Worldwide majority of the healthcare organizations facing the big challenge of high employee turnover which is chiefly due the workplace dissatisfaction but it directly have many sub stressing factors which create this negative occupational outcome ${ }^{9}$. The 
consequences of job stress have multidimensional impacts which connect both the employee and employers. For employees stress serves as originator for many health related disorders like diabetes ${ }^{10}$, hypertension ${ }^{11}$, cardiac disorders ${ }^{12}$, mental health problems $^{13}$ and other harmful ailments ${ }^{14}$, while decreased in work productivity, dissatisfaction of customers or end users and decline in revenues are the major troubling aspects for employers ${ }^{15}$.

For medical personnel especially doctors the professional responsibilities are much valued, important and critical because they are dealing with improving the quality of life hence to a great extent of focused on their job demands are the part of daily business. Those who practice medicine have more stress to experience as compared to someone who is else from the profession because a doctor's role is more sensible and sensitive for not only the patient's health, but society's point of view and in collectively for nation also ${ }^{16}$. The concept of job related stress was broadly studied parameters in medical and management sciences as stress in medical profession and its impact is the talk of the town from several decades. Different nature of researches is available through past literature which highlights the importance and interest of present idea but to address the need and validate the past findings are the essential requirements that establish the current objective of the study. Therefore to fill the space the current theme deals with the assessment of job stress among doctors working at the different tertiary care hospitals of Karachi and in near future an extensive national survey will strengthen the present concept.

\section{OBJECTIVE OF THE STUDY}

To determine the job stress among different doctors working in tertiary care hospitals of Karachi and to compare the job stress on the basis of different demographical factors that are associated with them.

\section{METHODOLOGY}

The data were collected from the doctors of different tertiary care hospitals of Karachi and the participants were chosen irrespective of their occupational affiliations, age, marital status and gender.

\section{SAMPLE SIZE}

Sample size was calculated by using mean scores of perceived stress found by distinct Pakistani study as $30.84 \pm 7.01 .17$ Using 95\% Confidence interval and 1.25 unit margin of error, the computed sample size was 121 . Adding 10\% non-response rate, the sample size was augmented upto 160 participants.

\section{STUDY INSTRUMENTS}

The survey is based on the pre-tested and standardized questionnaire on job stress (JS) which has been used as an instrument to collect data. It was available through American Institute of Stress (AIS). Special permission has been taken to use questionnaire for this research study from the AIS officials (A copy of a questionnaire and permission mails are available on request). JS questionnaire consists of total ten (10) items. Socio- Demographic information of study participants was also included. Responses to all items were equally scored on 10 points Likert scale (1 to $4=$ strongly disagree, 5 to 7 $=$ Agree somewhat and 8 to $10=$ strongly agree) with the statement.

\section{PARTICIPANTS}

The graduated and post graduated medical doctors from different tertiary care hospitals of Karachi were selected and the information from participants was collected through convenient sampling method. Verbal consent was taken from study subjects before handing over the questionnaire, with an assurance for confidentiality of information and their professional acquaintance. The entire duration of data collection covered the period from December 2011 to May 2012. 


\section{SUBJECTS INCLUDED}

A total of 160 professionals were asked to fill the questionnaire. The recruitment was done irrespective of age and gender. One hundred and thirty five (135) respondents filled the complete questionnaire.

\section{SUBJECTS EXCLUDED}

In this study, 19 of them had regretted there availability and 06 of them did not report their response appropriately hence they were excluded as study participants. $84 \%$ was the total rate of return of questionnaire for this study. Due to the differences in stressors related to the variable job responsibilities, those study subjects that were also linked with management positions were excluded.

\section{STUDY DESIGN}

The study design of this research was cross sectional and non-experimental because no new changes were introduced. Participants that filled the provided questionnaire made up the convenience sample.

The research setting for this study mainly includes standardized survey instrument, in the form of a questionnaire, which was easily administered and scored. Interview based on questionnaire was utilized because it is the most economic, efficient and effective method for collecting the data. The subjects remained anonymous, were asked to complete the questionnaire and assurance was provided to keep all responses confidential.

\section{STATISTICAL ANALYSIS}

Data were entered in EpiData v. 3.1 and analyzed in Predictive Analytics Soft Ware (PASW 18.0). Mean \pm Standard Deviation (SD) were computed for measurement variables such as age and job stress scores. Frequencies and Percentages were computed for categorical variables like gender, marital status, qualification and stress level. Cronbach's Alpha was calculated for detecting the consistency among the responses against 10 items in job stress questionnaire. Normality of the job stress score was checked by Shapiro-Wilk's Statistics and considered to be normally distributed as $P$ value was more than 0.05 ( $P=0.402)$. Two independent samples Student's $t$ test was run to detect any differences in job stress score between different demographic characteristics of participants.

Chi-Squared test was executed to find any association between demographic characteristics and job stress levels. Gamma statistic was computed to measure degree of strength of such association. Dummy Variables Regression Analysis was performed to assess amount of effect of significant demographic characteristics on job scores. $P$ value less than 0.05 was considered as portraying chances of significantly presence of above differences or associations.

\section{RESULTS}

A total of 135 participants completed the questionnaire. Among them 90 (66.7\%) were females, $64(47.4 \%)$ were married, 65 (48.1\%) were postgraduates and $55.6 \%(n=75)$ had less than 5 years of experience (Fig. 1). The mean age of the participants was $31.52 \pm 10.66$ years. The value of Cronbach's Alpha was $79.65 \%$, stipulating high level of reliability on the responses obtained from the participants.

Overall job stress score was $52.56 \pm 16.35$. This score is evenly found between males and females (Table I). Unmarried professionals were significantly more stressed than married professionals $(P<$ 0.0001). Similarly, participants with only graduate degree found to have higher stress than postgraduate medical doctors. Eventually, professionals with more years of experience were significantly less prone to be stressed than the junior professionals of their field ( $P$ $<0.0001)$. 


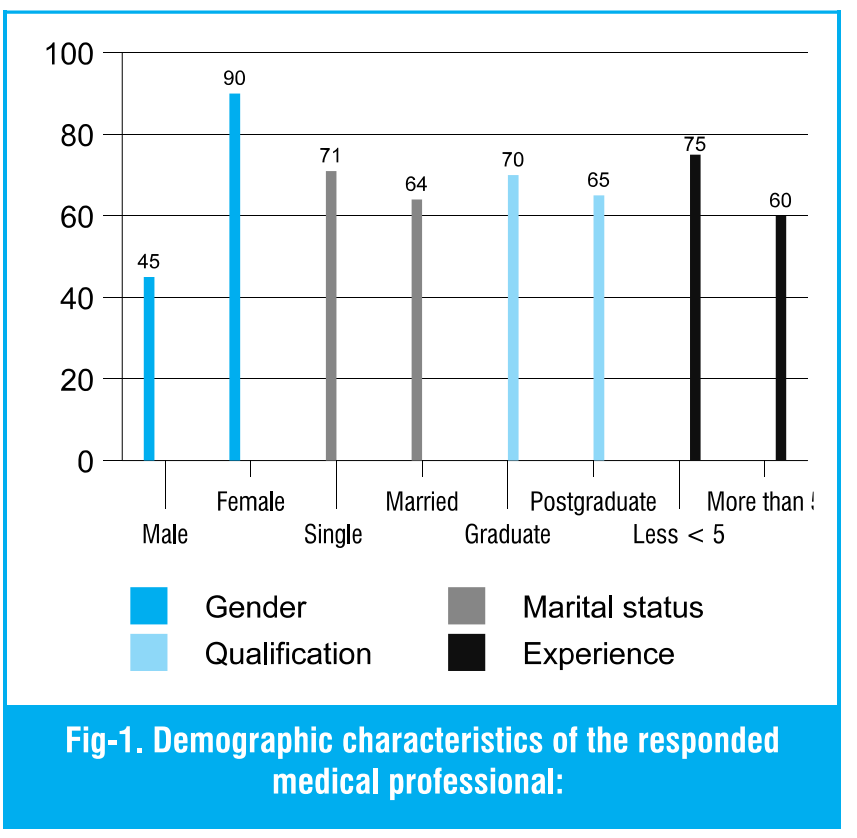

\begin{tabular}{|l|c|c|c|c|}
\hline \multicolumn{2}{|c|}{$\begin{array}{c}\text { Demographic } \\
\text { Characteristics }\end{array}$} & \multicolumn{3}{c|}{ Scores of job stress } \\
\cline { 2 - 5 } & Mean & S.D & P-value \\
\hline Gender & $\begin{array}{c}\text { Male } \\
\text { Female }\end{array}$ & 50.16 & 15.90 & 0.230 \\
\hline Marital Status & $\begin{array}{c}\text { Single } \\
\text { Married }\end{array}$ & 57.85 & 16.55 & \\
\hline Qualification & $\begin{array}{c}\text { Graduate } \\
\text { Post- } \\
\text { graduate }\end{array}$ & 57.69 & 15.96 & $<0.0001$ \\
\hline Experience & $\begin{array}{c}57.66 \\
\text { < 5 years } \\
>5 \text { years }\end{array}$ & 57.68 & 18.10 & 0.001 \\
& 46.15 & 16.68 & $<0.0001$ \\
\hline
\end{tabular}

Table-I. Job stress scores between different demographic characteristics of medical professionals: Job Stress $=$ 59.56-6.43 Experience - 6.03 Marital Status - 2.71 Qualification

\begin{tabular}{|c|c|c|c|c|c|c|}
\hline \multicolumn{2}{|c|}{ Demographic Characteristics } & \multicolumn{5}{|c|}{ Level of Job Stress } \\
\hline & & \multirow{2}{*}{$\begin{array}{c}\text { Handle stress on } \\
\text { job well }(\mathbf{n = 1 3 )} \\
3(0.067) \\
10(0.111)\end{array}$} & \multirow{2}{*}{$\begin{array}{l}\text { Moderately well } \\
\qquad(\mathbf{n = 8 2 )} \\
33(0.733) \\
49(0.544)\end{array}$} & \multirow{2}{*}{$\begin{array}{c}\text { Encountering } \\
\text { problems that need } \\
\text { to be addressed and } \\
\text { resolved }(\mathbf{n}=\mathbf{4 0}) \\
\\
9(0.20) \\
31(0.344)\end{array}$} & \multirow{2}{*}{$\begin{array}{l}\text { P value } \\
0.106\end{array}$} & \multirow{2}{*}{$\begin{array}{l}\text { Gamma } \\
0.189\end{array}$} \\
\hline Gender & $\begin{array}{l}\text { Male } \\
\text { Female }\end{array}$ & & & & & \\
\hline Marital Status & $\begin{array}{l}\text { Single } \\
\text { Married }\end{array}$ & $\begin{array}{c}2(0.028) \\
11(0.171)\end{array}$ & $\begin{array}{l}39(0.549) \\
43(0.671)\end{array}$ & $\begin{array}{l}30(0.423) \\
10(0.165)\end{array}$ & $<0.0005$ & $0.610^{\star \star}$ \\
\hline Qualification & $\begin{array}{c}\text { Graduate } \\
\text { Postgraduate }\end{array}$ & $\begin{array}{c}1(0.014) \\
12(0.185)\end{array}$ & $\begin{array}{l}41(0.586) \\
41(0.631)\end{array}$ & $\begin{array}{c}28(0.40) \\
12(0.185)\end{array}$ & $<0.0005$ & $0.568^{* \star}$ \\
\hline Experience & $\begin{array}{l}<5 \text { years } \\
>5 \text { years }\end{array}$ & $\begin{array}{l}1(0.013) \\
12(0.20)\end{array}$ & $\begin{array}{c}46(0.631) \\
36(0.60)\end{array}$ & $\begin{array}{c}28(0.373) \\
12(0.20)\end{array}$ & $<0.0005$ & $0.519 * \star$ \\
\hline
\end{tabular}

Stratifying the job stress into three levels, $13(9.6 \%)$ can handle stress on job well, $82(60.7 \%)$ were found moderately well and 40 (29.6\%) were found encountering stress problems that need to be addressed and resolved. The proportions of job stress levels in females were not significantly different than in males. Only $16 \%(n=10)$ married professionals were encountered with severe stress. This proportion is significantly higher in unmarried medical employees $(P<0.0005)$. Gamma coefficient depicted that changes the marital status from single to married the job stress decreases at higher degree (Table II). Regression analysis estimated this decrement amount is equal to 6.03 score. Similarly, each 4 out of 10 individuals who were only graduated suffered severe job stress levels. Senior professional encompassed 
this stress at lower level $(P<0.0005)$. The degree of strength of this association decreases significantly with 0.568 units. Though regression analysis revealed that job stress score was only 2.13 units decreased from graduate to postgraduate qualification. Twenty eight $(37.3 \%)$ doctors having less than 5 years of experience suffered severe stress. Only 20\% ( $n=12)$ of high experienced doctors encountered such problem $(P<0.0005)$. Accordingly, this effect decrease significantly with 0.519 degree of strength of association and the scores decreased upto 6.43 units with increment of experience.

\section{DISCUSSION}

Day by day modifications in the working practices and the impact of worldwide recession enhances the idea of work associated stress. There are multiple causes of stress but variation in job life and practices may be considered as an effective stimulator. The study is related with the medical doctors working in the metropolitan Karachi city and the rationale behind this effort is probing the demographic factors influencing the professional life of doctors. The study targeted the medical professionals of different hospitals of Karachi among them the frequency of the female participants was more than male respondents. As can be inferred from the results of this study postgraduates to graduates respondents ratio of doctors were nearly equal. Interestingly the reliability of results was analyzed statistically by Cronbach's alpha value which was greater than $70 \%$, hence it strengthen the reliability of responses.

Despite being solely focus on the managerial impact and behavioral characteristic of stress there are many biological studies which correlate the effects of stress on human cellular machinery. Researches on stress supports its association with different health disorders as many scientific literature relates the accumulation of stress with different health risk like chronic association of stress with biological system may results in diabetes, hypertension, cardiac disorders and other social problems ${ }^{23}$. One of the major findings of this study supports that majority of respondents (i.e., $60 \%$ ) handles job stress moderately well but focus and attention is required on second face of coin which describe that each 3 out of 10 respondents approximately have encountering stress associated problems that need special emphasis from the top management of healthcare system and required to be resolved by the help of different motivational technique or training programs. Considering stress as health hazard, these both above discussed frequencies of respondents establishing the concept related to the development of stress in doctors and have direct and indirect impacts on the productive capacities as well as working efficiencies in future, so it work as a threat if persistent accumulation of stress remains. Interestingly the comparison of respondents on the basis of marital status, unmarried doctors were expressed more stress significantly $(P<0.0001)$ than married ones.

Researches also focus special attention on spouse support, as it is more valuable tool in reducing the work related job stress, upgrading good balance between social - professional need of a person by achieving the responsibilities in more flexible and manageable way ${ }^{18}$, hence, it was also observed similar to this current context and make stronger our findings. Job associated stress also has an impact on person's social life, many reasons are structured to support this finding as it may be due to the lack of support or it may be due to the non- sharing of daily experiences with the family partner and lack of psychological strength in term of social support ${ }^{19}$, however in future special emphasis with probing is required on this comparison, hence proceed with this idea is another important topic to address the need of this profession.

Similarly the graduate medical doctors have higher stress levels as compared with postgraduate medical doctors, it may be due to the extra operational responsibilities and additional working of graduate 
doctors just to fulfill the occupational demands or it may be due to the person's self-attention to earn more income in order to support the financial needs of family members.

The important aspect of this study is the experience of high level of stress in junior (less than 05 years) medical professionals in comparison with those professionals that have more than 05 years of experience. This may be influence by many factors in junior doctors like less career satisfaction and multiple loads of studies with attending daily patient's clinics, overworked and under-supported profession may enhances the stress on them which not only make them unhappy with their professional affiliations but many studies emphasizes the negative correlation of stress on patients care and increase in workplace accidents $^{20}$. The same observation was also reported in another recently published study conducted with similar data settings among nursing care professionals of Karachi, Pakistan ${ }^{19}$. It implies that not only medical doctors but all related junior health professionals are more under stressed than their seniors.

Those doctors that have job associated stress and Continuation of studies with simultaneous involvement in professional obligation may also decreases the sleep quality and quantity and less connection with family may be possible factors for less experience doctors that have high job stress ${ }^{20}$. Those doctors that have greater professional experiences had low job stress because they may be more satisfied with their career and most of them have multitasking responsibilities (supervising clinical care, involve in teaching and organizational leadership role) with support and assistance from their junior staff members, which enhances the confidences on professional liabilities as well as decreasing the dissatisfaction in term of stress with profession. Doctor's job is dependent on dealing with different kinds of people. Especially for those professionals that have least experience in medical field have more distress because dealing with different kind of patient serve as a psycho-social stressor particularly for those that have greater patient volume with multitasking responsibilities. Here, one cannot forget to discuss the impact of financial rewards or incentives prominently among junior doctors on career satisfaction which abates the accumulated distress due to extra working or high patient volume with lack of experience.

Job stress levels in females were not significantly dissimilar than in males, this is among one of the important finding of our study which indirectly emphasizes the gender equality in this noble profession. This outcome may be due to the decrement in workplace associated emotional pressure, complaints at work and fear of professional hurdles which ultimately equate the stress level as in male gender. Different studies viewed organizational dissatisfaction as the major cause of job related stress as compare with the patient care because the magnitude of responsibilities and the potential associated job strain markers like lack of participation in decision making with centralize management policies, low professional autonomy, and conflict at work or high work pressure resulted in the induction of occupational stress ${ }^{3,688}$.

A study conducted in China concluded that with the increment of qualification about 3 fold increment of stress was observed. Though, increase in job rank decreases the job stress with equivalent ${ }^{21}$. We observed equally converse relationship with respect to academic qualification. However, stress related to job experience reduced 2 times less stress as portrayed by Chinese. A similar panorama is reported in a 5 year cohort study in Norway that changing the position to higher level increases the stress upto $2.71 \mathrm{fold}^{22}$.

Gender and age were put as insignificant factors for studying job stress by the Norwegians and the same 
was observed in current study.

Therefore it has been suggested that findings and elimination of specific stressors from the workplace site which influence the job stress among professionals is the key responsibility of all the concerned stake holders of that particular profession.

\section{CONCLUSIONS}

Stress in medical profession is never underestimated; doctors may have high levels of stress due to high professional pressure. The results concluded that up gradation in academic qualification lowers the occupational stress; hence the medical graduates possess more job related stress. Experience and marital status are two important demographic factors that reduce the professional stress among medical doctors.

\section{Copyright@ 14 Nov, 2012.}

\section{REFERENCES}

1. Ismail A, Yao A, Yunus NKY. Relationship between occupational stress and job satisfaction: An empirical study in Malaysia. Romanian Economic Journal 2009; 12: 3-30.

2. Marine A, Ruotsalainen J, Serra C, Verbeek J. Preventing occupational stress in healthcare workers. Cochrane Database Syst Rev 2006; 4.

3. Mishra B, Mehta SC, Sinha ND, Shukla SK, Ahmed N, Kawatra $A$. Evaluation of work place stress in health university workers: A study from rural India. Indian J Comm Med 2011; 36: 39-44.

4. Kirkcaldy BD, Martin T. Job stress and satisfaction among nurses: individual differences. Stress and Health 2000; 16: 77-89.

5. Schreuder KJ, Roelen CAM, Koopmans PC, Groothoff JW. Job demands and health complaints in white and blue collar workers. Work 2008; 31: 425-432.

6. Nasurdin AM, Ramayah T, Beng YC. Organizational structure and organizational climate as potential predictors of job stress: Evidence from Malaysia. Int $J$
Commerce Management 2006; 16:116-129.

7. Rosta J. Working hours of hospital doctors in Germany. DtschArztebl 2007; 104: 2417-23.

8. Williams ES, Rondeau KV, Xiao Q, Francescutti LH. Heavy physician workloads: impact on physician attitudes and outcomes. Health Serv Manage 2007; 20:261-269.

9. Ahmad T, Riaz A. Factors Affecting Turn-Over Intentions of Doctors in Public Sector Medical Colleges and Hospitals. Interdisciplinary J Research in Business 2011; 1: 57-66.

10. Batch BC, Kincaid B, Surwit RS. The role of stress in the development and management of diabetes mellitus. IDM 2009; 21:124-34.

11. Greiner BA, Krause N, Ragland D, Fisher JM. Occupational stressors and hypertension: a multimethod study using observer-based job analysis and self-reports in urban transit operators. Social science \& medicine 2004; 59: 1081-1094.

12. KivimÃ€ki M, Leino-Arjas P, Luukkonen R, RiihimÃ€i H, Vahtera J, Kirjonen J. Work stress and risk of cardiovascular mortality: prospective cohort study of industrial employees. BMJ 2002; 325: 857-60.

13. Tyssen R, Vaglum P, GrÃ nvold NT, Ekeberg Ã. The impact of job stress and working conditions on mental health problems among junior house officers. A nationwide Norwegian prospective cohort study. Medical education 2000; 34: 374-384.

14. De Castro AB, Gee GC, Takeuchi DT. Job-related stress and chronic health conditions among Filipino immigrants. J Immigrant Minority Health 2008; 10: 551-558

15. Jiang B, Baker RC, Frazier GV. An analysis of job dissatisfaction and turnover to reduce global supply chain risk: Evidence from China. J operations management 2009; 27:169-184.

16. McCue JD. The effects of stress on physicians and their medical practice. New Engl J Med 1982; 306: 458-463. 
17. Shah M, Hasan S, Malik S, Sreeramareddy CT. Perceived stress, sources and severity of stress among medical undergraduates in a Pakistani medical school. BMC medical education 2010; 10: 2.

18. RẪik J0, Tyssen R, Hem E, Gude T, Ekeberg Ã, Moum $T$, Vaglum $P$. Job stress in young physicians with an emphasis on the work-home interface: a nine-year, nationwide and longitudinal study of its course and predictors. Industrial Health 2007; 45: 662-671.

19. Azmi MB, Shamim S, Hussain M, Masood MA, Mirza Z. Factors and Demographic Characteristics Related to Nursing Workplace Satisfaction: Perspectives of Nursing Care Providers at Tertiary Care Hospitals of Karachi. J Dow Uni Health Sciences 2011; 5: 92-96.
20. Stucky ER, Dresselhaus TR, Dollarhide A, Shively M, Maynard G, Jain S, Wolfson T, Weinger MB, Rutledge T. Intern to attending: assessing stress among physicians. Academic medicine 2009; 84: 251-57.

21. Wu H, Zhao Y, Wang JN, Wang L. Factors associated with occupational stress among Chinese doctors: a cross-sectional survey. Int Arch Occup Environ Health 2010; 83: 155-164.

22. Solberg IB, Ro KI, Aasland O, Gude T, Moum T, Vaglum P, Tyssen $R$. The impact of change in a doctor's job position: a five-year cohort study of job satisfaction among Norwegian doctors. BMC Health Services Research 2012; 12: 41.

23. Azmi MB, Qureshi SA, Lateef T, Arshad HM. Health Hazard of work related stress. JDUHS 4:115-118.

\section{AUTHOR(S):}

1. DR. FARHAT KHAN

In- Charge, Human Resource,

Civil Hospital Karachi, 74200, Pakistan.

2. MR. MUHAMMAD BILAL AZMI

Assistant Director, Quality Enhancement Cell,

Dow University of Health Science, 74200, Karachi, Pakistan.

3. MISS MEHWISH HUSSAIN

Senior Lecturer, Department of Research,

Dow University of Health Sciences, Karachi, 74200, Pakistan.

4. Miss Sarah Shamim Azmi

Faculty, Department of Special Education,

University of Karachi, Karachi, 75270, Pakistan.

\section{CORRESPONDENCE ADDRESS:}

Mr. Muhammad Bilal Azmi

Quality Enhancement Cell,

Dow University of Health Science, 74200, Karachi, Pakistan azmibilal@gmail.com

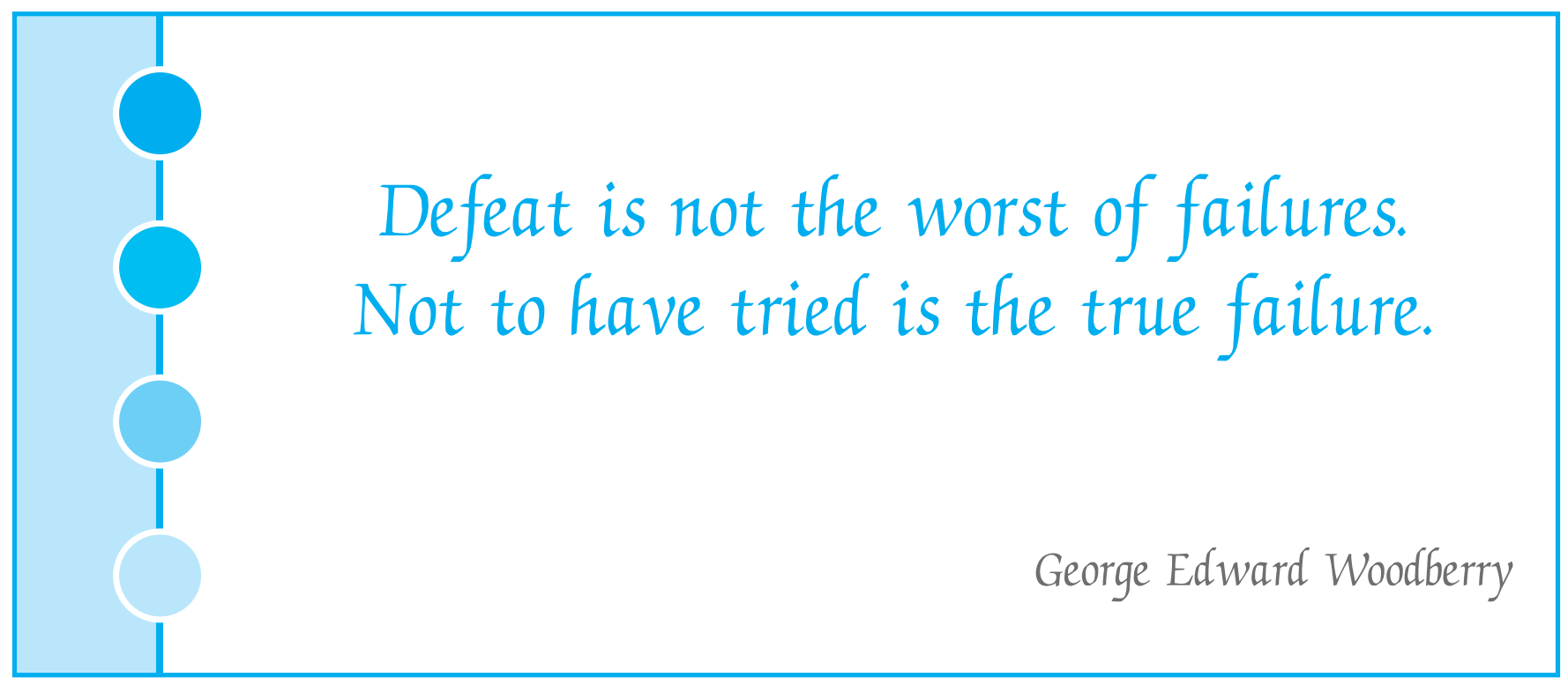

